\title{
Discurso do Orador da Turma de Bacharelandos de 1938
}

Proferido na solenidade da colação de grau realizada, em 5 de janeiro de 1939, no Teatro Municipal de São Paulo.

\section{F. L. de Almeida Salles}

Éramos adolescentes ontem. Nervosos e tímidos, ainda agitados pela emoção dos vestibulares, comparecíamos diante do olhar penetrante de Júlio MaIA para a formalidade de inscrição na Academia. Dêsse instante até hoje 5 anos se desenrolaram - longos e decisivos. Eles são a nossa vida acadêmica. Vida que será preciso deixar, vida que viemos deixar aquí, nesta atmosfera que não consegue ser festiva, apesar de impregnada de confôrto e de amor, como não conseguem ser festivas as gares agitadas e rumorosas e os portos varados de apitos e de adeuses.

Ficou lá atrás - tão distante! - a mão magra de Júlio MaIA crescendo sôbre os nossos olhos espantados. E agora é esta cerimônia de fim, de encerramento, de despedida e, principalmente, de investidura numa missão pesada de responsabilidades.

Entretanto, neste instante em que abandonamos a Academia, perturbados ainda em face dos misteriosos dias a vir, vendo que com os simples estudantes que éramos se extingue a última reserva de irresponsabilidade adolescente, neste instante é que sentimos intensamente - antes apenas 
compreendiamos - o que a Academia representava como abrigo contra os terriveis ventos das lutas práticas, como despreocupação em face da vida séria, como adiamento de solução para o problema do nosso destino.

É êste o grande sentimento que nos perturba e enche nesta hora de preocupações o nosso espírito. Sentimento irreprimivel e dominador, mesmo naqueles, dentre nós, para os quais se rasga fácil e sem choques a aceitação dos novos caminhos. Não é apenas a Academia que se abandona, é um estado de espírito que ela condicionava, uma atitude particular que assumíamos à sua sombra: o triste e definitivo adeus à escola tão cheio de significação e de ressonâncias, isto tudo que enche de emoção a voz das gerações em todas as épocas, a morte das últimas despreocupações, o fim iniludivel de um período, a adolescência que já não é mais possivel deter.

Como não confessar, pois, desde logo, com sinceridade, que é agitados por êste rude e invencivel sentimento que também aquí comparecemos? Lá fora, entretanto, as ocupações e os empregos já nos são familiares. Não se extingue com a vida acadêmica o ócio estudantino que morria ao abandonarmos os bancos ginasiais. Mas, não nos iludamos, nem delimitemos o conceito de vida prática. Com a Academia se extingue a última defesa que possuíamos contra ela, contra a sua invasão absorvente. É agora que a iremos aceitar, porquê é só agora que o seu poder de absorção se revelará plenamente - neste instante em que cortamos a última amarra que nos prendia ainda a essa terra alegre e ingênua da adolescência e nos atiramos ao mar áspero, o mar sem refúgios e sem ilhas, o mar sem paisagem, nú e árido, que nos devolverá um dia ao solo firme de onde partíramos, gastos e sem côr, como os velhos navios aposentados.

Assim compreendemos esta hora, sem ilusões e sem audácias juvenís. Tememos a vida prática, porque nada mais fizemos até agora do que nos armarmos para enfren- 
tá-la. Nestes longos anos de adestramento e de preparação, abrindo a inteligência para a compreensão do homem e do mundo, nas suas relações recíprocas, fomos plasmando a nossa personalidade, o nosso perfil moral e espiritual, afirmando o nosso modo de ser. Essa personalidade precisa ser resguardada. A vida prática poderá ser a sua grande inimiga, se não nos compenetrarmos de que acima do profissional está o homem e de que é preservando a nossa humanidade que dignificaremos a própria profissão. A vida prática é uma usurária impiedosa. Na sua atmosfera opressiva e envolvente, nós usamos a tal ponto, que acabamos comprometendo a nossa visão humana das coisas. $O$ homem não pode ser posto ao serviço da profissão, é evidente, e sim a profissão ao serviço do homem. A profissão é, para o homem, um meio de realizar os fins a que se destina. E mesmo quando há na própria profissão uma finalidade especifica de ordem social - e é o caso da advocacia que não pode ser reduzida aos seus secundários objetivos utilitários - a garantia do cumprimento dessa finalidade, inerente à profissão mesma, será dada pela fidelidade do profissional ao humano.

Parecerá ocioso insistir nisto, mas a que se reduz toda a ofensiva do anti-humanismo moderno, senão a êsse esmagamento do que há de essencial no homem, pela hipertrofia e pela valorização do que lhe é acidental - a profissão na ordem individual, a nacionalidade na ordem internacional, a classe na ordem social e a raca na ordem biológica? BerDIAEFF fala no "jugo do Quotidiano" de que é preciso se libertar a pessoa humana, pela realização da sua vocação cósmica e social. Se há, pois, na vida prática, êsse ritmo cego de fruição material e se a profissão é a forma pela qual êsse labor utilitário se reveste, como não perceber os perigos de uma submissão da natureza humana ao ritmo exclusivo da atividade profissional, jungida necessariamente a tais objetivos materiais pela maldição biblica do "comerás teu pão com o suor do teu rosto"? Já que "o homem 
pecador não pode gozar de uma economia paradisiaca", na expressão de Berdiaefr, e já que o fim último do trabalho é a satisfação das necessidades materiais da vida pela aquisição dos bens correspondentes, está o trabalho sujeito a se escravizar, não às necessidades do homem, mas às derivações e projeções egoísticas e cúpidas dessas necessidades, passando a ser um fim em si mesmo e submergindo a liberdade humana e a sua destinação superior.

Acentuemos, porém. É impossivel o exercício fecundo da atividade profissional, sem o sentimento de amor por ela. A eficiência do nosso trabalho como profissionais será avaliada na medida do nosso interesse e do nosso amor pela profissão mesma. Amamos a profissão, entretanto, porquê ela é uma via para a realização da nossa humanidade. E é por ser sagrado êsse destino que o caminho seguido deve ser reto e claro e nunca se abrir em picadas sombrias ou derivar para os desvãos ocultos das complacências ilícitas e das ações e omissões indignas.

Esta concepção teleológica da profissão deita raízes no humanismo cristão e se funde, intimamente, com o sentido da civilização brasileira, que renega o pragmatismo utilitarista e a filosofia do êxito, nasciảos do progresso da técnica e do apogeu industrial.

Aquí estamos, pois, nós, a geração acadêmica de 1938, comovidos, porque esta é uma hora de despedida, pensativos, porquê é impossível não refletir sôbre a gravidade da vida que se inicia.

$\mathrm{E}$ é nesta hora-limiar, nesta hora-fronteira, compreendendo com amargura que é preciso partir, pois há novas gerações subindo no fluxo incessante das idades, mas ouvindo lá fora, temerosos, o rumor áspero da Vida, indecisos ainda sôbre os rumos a seguir, é nesta hora que, segundo o rito das formaturas acadêmicas, devemos falar. 
Vêde que não pode deixar de ser rouca e grave esta voz, molhada de emoção e de inquietude, como é sempre a voz dos homens nos momentos de perplexidade e de decisão. Voz múltipla e densa, pois não é uma voz isolada, é a voz de toda uma geração acadêmica traçando, com franqueza, o itinerário das suas aspirações e das suas esperanças, e fazendo a sua profissão de fé no Direito, para a defesa do qual se inscreveu, como os cruzados, para a guerra santa.

Somos uma geração grave, e se sorríssemos, sorririamos falso. Não é êste o instante de um depoimento, mas poucas gerações acadêmicas foram, como a nossa, tão imperativamente solicitadas a se definir diante dos acontecimentos em trânsito no cenário da vida brasileira. Não nos foi possivel, como nas gerações anteriores, permanecer à margem das agitações e das lutas. Não cultivamos o verso e a ironia, toda e qualquer disponibilidade nos foi inaccessivel. Como permanecer indiferente, se tão violentamente éramos sacudidos pela agitada realidade? Durante 43 anos as gerações acadêmicas viveram à sombra de uma Constituíção: a Constituição de 1891. Nós, no nosso período acadêmico, vimos ruir o edifício de 91 e, em seu lugar, se ergueram duas Constituições, a primeira, refletindo principalmente as novas tendências sociais, e a segunda, as novas tendências políticas, postas em equação diante do abandono, por grande nações do Ocidente, dos velhos principios do liberalismo democrático.

Paralelamente, pois, à experiência de cultura e de meditação que recebíamos dos mestres, pela compreensão do direito em todos os seus múltiplos aspectos e formas, vivemos intensamente os fatos, que pareciam se condensar e se suceder diante dos nossos olhos, como a nos revelar, num instante da história, todo o mistério das construções jurídicas e das estruturas sociais.

Como não considerar, portanto, as ressonâncias dessa experiência na nossa formação juridica e o privilégio de termos sido testemunhas, durante o nosso curso, de tão decisivos momentos da vida pública brasileira? 
Haviamos ingressado na Academia quando São Paulo deixava as trincheiras e a atmosfera de uma guerra civil, que constituíu o mais tipico e significativo exemplo do conflito, que tantas vezes se delineara, entre as prerrogativas estaduais e a hegemonia do poder central.

Já trazíamos, pois, essa experiência singular e única nas circunstâncias em que se desenvolveu. Logo depois, e enquanto a ordem constitucional sofria as transformações de 34, assistimos à eclosão das correntes reformistas, que levaram para o debate público, para a agitação das ruas, para as campanhas de jornal as grandes questões de direito público e os problemas de organização, direção e destinação do Estado.

Como sempre, as Arcadas tudo escutaram - sismógrafo sensivel registrando os mais sutís estremecimentos da vida nacional. E pelos corredores, nós, e a nossa ânsia juvenil de dedicação e de fervor.

A silhueta de Álvares de Azevedo - exclamava o $X I$ de Agôsto em 1936, traduzindo a agitação ambiente - é mais um símbolo de inquietude revolucionária do que uma efígie de poeta. Os oradores acadêmicos trazem na voz acentos de apostolado. O espírito de comício invadiu as nossas reuniões. As opiniões se chocam. Os grupos se formar e o proselitismo passou a ser a alavanca da solidariedade reciproca. Fundam-se associações literárias e elas agasalham, sob a égide da poesia, espiritos combativos e inquietos. Reúnem-se os seus associados e as reuniões se transformam em meetings de pregação política.

$E$ isso era exato. Muitas vezes comparecíamos às aulas, vindos da estação, onde desembarcávamos de volta de comícios e de campanhas pelo interior. Vivemos intensamente os fatos, de olhos abertos para a compreensão dessa fase trepidante da vida brasileira.

Por tudo isso, porém, porquê testemunhamos com lucidez toda essa agitação, porquê olhamos para nós mesmos e nos vimos e olhamos em tôrno de nós e vimos o Brasil, 
porquê sentimos o direito vivificado ao calor da of uscante realidade, por tudo isso é que não sorrimos, por tudo isso é que somos uma geração grave.

Mocidade e gravidade, entretanto, não são expressões antinômicas. A gravidade não é apenas o sinete da madureza. Hoje os moços são graves sem antecipações no tempo. No mundo moderno basta saber olhar. O clima da hora em que vivemos, por ser apocalítico, é, por isso mesmo, um clima de profecia. Estadistas e pensadores falam, correntemente, em "sentido do tempo", “destino da época", "ritmo da civilização" A realidade se apresenta grávida de tendências contrastantes. Por isso todos parecem descobrir no presente prenúncios e ante-visões de instantes futuros, como se o "vir a ser" latejasse já nos estremecimentos da hora que passa.

Vivemos os fatos, pois. Recebemos uma experiência de vida como poucas gerações acadêmicas receberam, pela singularidade e pela importância dos acontecimentos de que fomos testemunhas. E compreendemos, após tudo, com ardor e convicção, que nada de autêntico e de verdadeiro seria possivel construir, sem a luta pelo direito, sem o amor pela justiça, sem o respeito sagrado à personalidade humana nas suas afirmações de liberdade e espiritualidade.

Com esta conviç̧ão deixamos a Academia. Recebemo-la dos mestres e os fatos se encarregaram de confirmá-la, banhando-a de fôrça e de vida. Pelo direito combateremos, armados dessa dupla e decisiva experiência -- forte como as couraças dos guerreiros antigos. Não vimos apenas o direito imobilizado nos textos legais. Vimo-lo em luta pela realização da justiça e vimo-lo através dos fatores geradores e informadores da sua própria transformação.

Ilustre paraninfo professor NóE Azevedo. Todas as gerações acadêmicas escolhem, dentre os mestres, aquele que lhes deverá falar na hora da partida. A nossa geração vos escolheu. Vinhamos para aquí, para a soleira desta porta e aquí nos iríamos deter, amontoados e indecisos, 
olhando, lá fora, as horas e os dias desconhecidos. Entretanto, ouvindo o nosso chamado, viestes indicar o necessário caminho. A vossa voz não será mais a do professor diante do direito. Será a do guia amigo e sorridente diante da vida. Vendo-vos entre nós, porém, nenhuma surpresa experimentamos, pois a vossa cátedra foi sempre um núcleo de solidariedade e de confiança e nunca, em momento algum, nos sentimos distanciados dela.

Queremos enaltecer, neste instante, a vossa inteligência e a vossa cultura. Entretanto, sendo culto, sois simples, e sendo um mestre, sois também, e por isso mesmo, um amigo. Descestes da cátedra de que sois, por todos os títulos, digno, e viestes vos confundir conosco no tumulto dêste adeus. Que poderiamos vos dizer, e que fôsse mais eloquente que êste pulsar rítmo de corações e esta aflita ansiedade com que esperamos a vossa mensagem de despedida?

E agora: o adeus à Academia. Como traduzinei a vossa emoção, meus amigos e colegas? Amanhã já não atravessaremos mais o Largo de São Francisco, apressados, porquê o último sinal da campainha já soou e os professores se encaminham para as salas de aula. Não nos encontraremos mais em grupos, pelos corredores e pelos pátios, sempre com tanta coisa a dizer uns aos outros, com tanta coisa a confessar aos colegas mais intimos que a Academia nos ofertou - as leituras da véspera, os passeios, as vitórias esportivas. Não nos veremos mais emocionados e inquietos, saindo da Biblioteca, onde, da leitura de um livro, sentimos nascer o veio de uma decisiva afinidade intelectual. Como é turva e imprecisa esta visão daquelas horas, dêstes anos! Tudo era perturbação, entusiasmo, exclusivismo, emoção. Foi junto daquela janela do $1 .^{\circ}$ andar que, pela primeira vez, conversamos com um anônimo estudante, que iria ser o nosso amigo de hoje e em cuja amizade nos descobrimos a nós mesmos. E êste que nos veiu mostrar, comovido, um 
poema de Claudel. E aquele que nos revelou, numa manhã inesquecivel, a densa atmosfera da creação proustiana e a sua ânsia, tão de todos nós em certo instante da vida, de captação do passado, na sua fuga desesperada e irremediável. E aqueles com quem saimos para as lutas políticas, na utilização, pelo ideal, da grande reserva de dedicação e de fervor que sentíamos arder em nós, ao sôpro das aspirações de grandeza e de dignidade do Brasil no mundo. E vós todos, ó colegas desaparecidos, Décio Pinto de Oliveira, Álvaro luiz de Vasconcelos, Roberto Horta de Oliveira, Pero Neto, Adolfo Mazza Júnior, vós que sois a grande ausência que nãos aceitamos apesar de a terdes justificado há já tanto tempo. E você, Pero Neto, cuja voz ainda parecemos ouvir, dizendo com voz trêmula os seus versos, tão reveladores de uma agitada sensibilidade. Lembro-me de uma noite, no camarote de um navio que nos trazia do Recife, em que êle me acordou para mostrar os versos que fizera, olhando o mar, sozinho, no navio adormecido.

E' esta atmosfera, meus amigos e colegas, cheia de vultos e de minutos inesqueciveis, que abandonamos, neste instante, ao proferir o nosso adeus à Academia.

Quando para ela entrámos, o velho convento franciscano ainda estava de pé. Nos seus corredores e nas suas salas de paredes esburacadas e grossas, no patio emoldurado pelas Arcadas, nas escadas de degraus gastos pelo passar das gerações, na fachada barôca transfigurada à luz da ardente glória dos poetas, em tudo sentíamos a presença do passado, impregnando o ambiente de misticismo e de austeridade.

Um dia, porém, as picaretas começaram a bater de encontro às paredes venerandas. Das salas de aula ouviamos aquele rumor surdo e cadenciado. Durante anos aquele côro monótono foi o nosso pano de fundo sonoro e triste. Do velho casarão franciscano, encorujado e feio, emergia uma estrutura viva e forte, como de um casulo parte o vôo livre e ágil de uma borboleta colorida. Andávamos sôbre 
escombros. Éramos transportados de um lugar para outro, acompanhando a marcha inflexivel das picaretas destruidoras. Aquela sala, onde ainda ontem ouvíamos a palavra dos mestres, hoje nós a encontrávamos devassada, as janelas arrancadas, dentro, a caliça caindo como neve, uma neve fina e envolvente.

Em nós também a vida operara transformações. Do adolescente impulsivo e perdulário, nascia o moço calmo e refletido, a ruga séria marcando, com o sinete do pensamento, a testa ampla e lisa da irrefletida adolescência.

Em nós, como na velha academia destruída, muita coisa morrera. Mas, o que morrera deixara marcas, e embebera com a sua presença a nossa vida, como os perfumes que se extinguem impregnando de essências o ar. Tínhamos que ser fiéis ao espírito da nossa adolescência, como a nova Academia teria que ser fiel ao espirito do velho convento franciscano.

Que significava ser fiel ao espírito da nossa adolescência? Significava ser lúcido, num mundo conturbado pelo desespêro e pelo ódio. Significava ser crédulo, numa atmosfera contaminada pelo sôpro de todas as negações. Significava ser puro, num instante de concessão aos imperativos materiais da vida. Significava ser franco, em face da reserva prudente, da desatitude cômoda, do silêncio feito de temor e de indiferença - máscaras da omissão e da cumplicidade.

“Sempre pensei - exclama Bernanos, o Bernanos dêsse livro espantoso que é o Les grands cimetières sous la lune - sempre pensei que o mundo moderno pecava contra o espírito da mocidade e que êsse crime o faria morrer. E' claro que a palavra do Evangelho: não podeis servir a Deus e ao dinheiro, tem seu equivalente naturalista: não podeis servir ao mesmo tempo ao espírito da mocidade e ao espirito de cupidez"

Que significava ser fiel ao espírito da velha Academia? Significava a fidelidade à tradição no seu sentido substan- 
cial e vivo - o amor à nossa civilização, brotada aquí mesmo no planalto agreste, naquele largo pequenino, em cuja terra o jesuíta plantara as paredes sagradas do colégio e semeara o germe espiritual de uma raça nascente.

Espírito da velha Academia. História agitada do Brasil. Sob as Arcadas fomos descobrir, como numa arca de pau santo, a tradição da terra. (As caravelas de Cabral passaram entoando hosanas ao mundo descoberto. Longe, o burgo pequenino dorme sozinho, na desolação do sêrtão tenebroso, a muralha fragílima de taipa toda enfeitada de corriolas - sentinela avançada da civilização americana). Alma da terra virgem, que se acantonara no planalto e ficara a embalar, serenamente, o berço do mameluco quinhentista e a ensinar-lhe a doutrina do perdão e da coragem.

O planalto viu tudo:

Viu a alma da terra jovem levantar-se mística do solo na hóstia que o padre Paiva alçava comovido e afundar-se no ocaso do burgo ramalhense, enquanto o Guapituba lânguido rolava; viu-a toda dispersa na manhã confederada de flexas e tacapes: os olhos aflitos nas cêrcas de taipa grosseiras e frágeis em frente das hostes de inveja do vil Jagoanharo; o ouvido assustado escutando na selva o "matuyú" que avança enquanto os "coruqueans" estremecem a terra com passos de chumbo; o côro assustado dos coromís medrosos e as rezas que as indias faziam reunidas na igreja durante o combate; as ondas serenas do Yperoig lambendo os versos da Virgem escritos nas brancas areias; viu-a toda desfeita no sangue e no fogo que os ruivos piratas de Thomaz Cavendish, nascidos no ódio, trouxeram dos mares; viu-a coberta de susto e de pasmo no brilho da arma assassina e frei Diogo rolando no sangue às portas da ermida da Luz; viu-a ras- 
gando o "caminho do mar" e transpondo a muralha da serra: o trabalho paulista descendo nos ombros de escravos em caixas de doce; viu-a enfrentando o cansaço e o perigo no avanço à procura da serra fatídica de Sabarábuçú; viu-a coberta de glória no sulco que as "bandeiras" abriram no corpo da terra: as botas de couro amassando distâncias e rasgando caminhos no seio da selva encantada: Raposo Tavares fitando do alto das nuvens andinas, as mãos em concha sôbre os olhos impassiveis, o oceano bramindo de encontro aos rochedos e acordando nas águas do rio Amazonas a Yara que dorme no seio das flores; e Lourengo Castanho, já velho e cançado. abrindo caminho no encalço do ouro; e o estranho Anhanguera creando prodígios nas matas incultas; e o heróico Pedroso lutando com os incas na encosta dos Andes; e Pais Leme apertando a sacola de couro ao peito extenuado enquanto a Vupabuçú, envolta em mistério serena dormia; e o Tordesilhas rebentando fragorosamente na poeira das entradas; e as "reduções" jesuitas destroçadas na ousadia irreprimivel das vitórias: o Guaira famoso sepultado entre as ruínas do rio Paraná, ao grito de guerra de Raposo e Manoel. Preto; os burgos espanhóis do Alto Tibagi ouvindo o brado de posse de Antonio Pedroso; a Tape longinqua envolta na pólvora negra do arcabuz bandeirante morrendo nas convulsões de Caazapaguassú e Caazapamirim; o Uruguai transposto no pulo espantado das léguas; e o Maruí jesuíta caindo aos golpes de Raposo, Manoel Pires, Pedro LEME no côro de imprecações que se erguia, assustado; viu-a no bôjo dos galeões de Fernando Mascarenhas correndo em auxílio do norte humilhado pelo invasor bátavo; viu-a marchando atra- 
vés dos "quilombos" desfeitos do imenso Palmares: Domingos Jorge Velho lutando 3 anos no cêrco de ferro e de fogo do rio Mundaú e extinguindo a República Negra, enquanto o Zumbí, esgotado e perdido, morria no fundo do abismo; viu-a tremendo no meio das vozes da gente espanhola que à fôrça queria fugir ao domínio do rei português: e Amador Bueno, que tinha nas veias o sangue de Pekerobí, fazendo brilhar às portas de São Bento a espada leal da nobreza e da honra; viu-a lutando em defesa das minas, enquanto o emboaba avançava sinuoso, tingindo de sangue o riacho das Mortes; viu-a no heroismo de sempre: os barcos errantes das monções desfeitas pairando sem rumo, repletos de ossadas, no lombo dos rios; o instinto do povo explodindo na heróica "Bernarda" ao ruflar dos tambores festivos; e o braço valente do príncipe moço despindo a espada da terra liberta, enquanto os grilhões se quebravam com ruído ao tropel dos cavalos e o riacho Ipiranga passava, assustado, por entre a poeira das margens; e a luta audaciosa de Tobias Aguiar contra as leis e reformas do Império, con as mãos sôbre os ombros humildes do grande FerJó; e a aurora brilhante da noite africana de séculos.

$O$ planalto viu tudo.

Sabieis por certo, $\delta$ frei Francisco das Neves, quando ordenastes a fundação do convento de São Francisco, que estáveis construindo a grande morada da tradição brasileira - antena sensivel captando a história trepidante da conquista americana?

E vós, ó sr. deputado José Feliciano Fernandes PinheiRo, que querieis dizer, justificando a proposta de fundação da Academia em São Paulo, com estas estranhas palavras: "pelas vantagens naturais e razões de conveniência geral?" 
Adeus à Academia.

"E' preciso muito esfôrço, escreve Mauriac no seu Journal, para nos resignarmos a viver num universo dotado de memória". E continua: Há sempre em todas as famílias um velho tio-avô ou um velho primo do qual se diz que é o último depositário da secreta história dos nossos antepassados desaparecidos. Deliberamos interrogá-lo antes que êle, também, desapareça. À medida que êle se aproxima do fim, o tempo passado é o grande tema das suas conversações: dir-se-ia que, antes de partir para sempre, desejasse se desembaraçar de um pesado depósito: "Eu me lembro que o teu pobre bisavô sempre me dizia." Mas nós não ouvimos, o espírito misteriosamente desviado do que não deve ser retido. $E$, afinal, essa última testemunha também parte; e ela pode dizer àqueles aos quais se vai reunir: "Ninguem na terra pensa em vós".

Senhores mestres. Esta geração acadêmica despede-se de vós e da Academia que tão dignamente representais, convencida de que o esquecimento não descerá sôbre ela as sombras do seu perfil impiedoso. Partimos, mas tão intensamente a Academia impregnou a atmosfera da nossa vida que, mesmo o espírito distante dela, estaremos traindo, ao repetir um gesto esquecido ou ao acordar uma alegria sufocada, estaremos traindo, em nós, a sua irremovíve] presença. 